\title{
A Study on the Factors Affecting E-logistics System in Chinese
}

\section{Logistics Industry}

\author{
YU LIU \\ Finance and Economic School, XI ZANG MIN ZU University, China \\ XIAN YANG City, 710082, China \\ Email:191017804@qq.com
}

Key Words: E-logistics System, Factors, Chinese Logistics Industry

\begin{abstract}
Regarding the current situation of E-logistics of Chinese logistics industry, there are still many problems to be concerned and resolved. This paper reviews the concepts and theoretical background of E-logistics System from previous researches. After acknowledging the essential issues on E-logistics System, it identifies the five key factors (Reliability, Maintainability, Software, Facility and Transportation) which influence E-logistics system. This research aims to provide theoretical and practical contributions for Chinese logistics companies to enhance understanding on E-logistics System. It also provides some useful theoretical implication and practical guidelines for the development of E-logistics System in Chinese logistics industry.
\end{abstract}

\section{Introduction}

E-logistics can be defined simply as the application of Internet based technologies to traditional logistics processes. Cheng and Yue explained the e-logistics system details in 2006. They pointed out the e-logistics system can be described by the process, the information system and the value.

With the increase of the global competition and the rapid progress of the logistics industry, Chinese logistics industry (CLI) is also facing the large challenge. Facing with the increasing intensity of competition after China's WTO accession, logistics companies try to consider how to create more effective services to their customers and try to build their own e-logistics system so that they can survive in the global logistics market. Therefore, there are many issues of e-logistics system which come into being in Chinese logistics companies. Considering the increasing environmental complexity and competitive pressure along with increased market opportunity, research on e-logistics system of CLI in an international context can provide many useful insights.

Based on this, the purpose of this study is stated below: Firstly, the study stated the definition and factors influenced e-logistics system according to related research. Secondly, the study examines the major factors affecting e-logistics system in Chinese Logistics Company (CLC). Finally, in this dissertation, an effort would be made to suggest CLC how to adopt e-logistics system by using the factors which are concluded in this study.

\section{The factors influencing the e-logistics system (ELS)}

\section{Reliability factors}

Reliability is the probability that an item will perform its intended function for a specified interval in a stated condition. The frequency of maintenance for a given item is highly dependent on the reliability of that item. In general, as the reliability of a system increases, the frequency of maintenance will decrease, and vice versa, Unreliable systems will usually require extensive maintenance.

\section{Maintainability factors}

Maintainability is an inherent design characteristic dealing with the ease, accuracy, safety, and economy in the performance of maintenance functions. Maintainability, defined in the broadest sense, can be influenced in terms of a combination of elapsed times, personnel labor-hour rates, maintenance frequencies, maintenance cost, and related logistic support factors. 


\section{Software factors}

For many systems, software has become a major element of support. This is particularly true where automation, computer applications, digital data bases are used in the accomplishment of maintenance and logistics functions. As with equipment, reliability and quality are significant considerations in the development of software.

\section{Facility factors}

Facilities include the planning, acquisition and management of permanent or semi-permanent real-estate and property assets required to support the system. These are required to support activities pertaining to accomplishment of active maintenance tasks, providing warehousing functions for spares and repair parts, and providing housing for related administrative functions.

5. Transportation and handling factors

Transportation requirements include the movement of human and material resources between the sources of supply and the various locations where maintenance activities are accomplished. In essence, transportation plays a key role in the area of logistic support, activities and is one of the key elements of the logistic functions aimed at expanding the production system as whole and can be considered as strategic activities linking all the operators along the value-chain.

3. The analysis on the key factors influencing the e-logistics system (ELS) in Chinese logistics industry

1) Reliability

For most enterprises, the understanding of "E-logistics" is still superficial and limited to the integration of transportation and storage. They only believe that E-logistics can create the added value. Whenas, most of companies still doubt that reliability can develop and improve ELP and LIS and deny the direct relationship between them. Now CLC are still thinking in a "traditional" way and primary stage. They only recognize ELP competition by taking advantage of Transportation effectiveness positions and as the factor (reliability) contributes to only one components of superior ELS performance.

Therefore, not only CLC but also the whole society should improve recognition of e-logistics. E-commerce is a revolution in the business field, and e-logistics is a revolution in the logistics field. The function of e-logistics covers the design, execution and management of the logistics demands of a customer's supply chain. Its key feature uses information and professional logistics knowledge to "provide quality services with minimum cost". CLC should first change their traditional mind and learn to have an in-depth understanding of logistics. And then they should upgrade development of ELS as the status of competitive strategy. Finally, the social development of ELS can be the arrangements for the agenda.

2) Maintainability and Software

The modern LIS should be the new-style general logistics management information system based on the Internet. The LIS in the design process should realize two objectives. First of all, the previous logistics business will be effective control over the flow of logistics, improve the efficiency of ELP and reduce logistics costs according to computer and network technology, business restructuring, redundant processes deleting. Secondly, it will really achieve customercentric service idea for attracting more customers.

Therefore, the effective LIS should be built up based on strengthening maintainability managements and upgrading software technology. Then developing LIS is linked to two critical conditions: the advanced management and software technology. At the present stage, CLC should enhance the personnel training. As we know, E-logistics personnel shortage is a serious problem in China. E-logistics personnel are complex of high-level talents. On the one hand, Logistic companies might consider introducing into e-logistics personnel; On the other hand, they could send the potential people to learn abroad.

For the advance software technology, most of CLC have weak competitive capability and financing ability. They could not invest redundant funds to purchase the advance software technology. Therefore, the survey results show software factor is no positive effect on added value in CLC. Then the Chinese government should provide some preferential treatments and policies to 
Chinese logistics industry for the development of LIS.

In this case, Logistic companies could learn the experience of E-logistics management from developed countries and eliminate funding problems with the support of government so as to find out the short cut to speed up the pace of development of LIS as far as possible. Meanwhile, Chinese logistics companies take advantage of LIS to accelerate ELP development so as drive the whole elogistics industry to move forward.

3) Transportation and Facility

Transportation and Facility plays a vital role. But transportation and facility do not have any significant effect on LIS and facility do not have any significant effect on ELP. These all attribute to the characteristics of the majority of logistics enterprises. : "smallness", "a few", "weaknesses", "separations". That means they lack concentrate and integrated network. They have no standard of business operation order and irregularities of management regulation.

Therefore, Chinese government and enterprises should establish ELS together. They should cooperate and invest together to build up the whole ELS. The government need invest adequate funds on the highway, railways, aviation, information network in order to ensure the traffic and the information smoothly and then form community-wide coverage transportation and information network. Meanwhile, Logistics enterprises should invest on the modern logistics technology and facility for improving ELP and customer services. In addition, in order to attracting more manufacturing companies and Internet businesses, logistics companies should improve business competitiveness and profitability and promote the development of e-commerce so as to accelerate the development of e-logistics industry.

To sum up, logistics companies should recognize the ELS is the outcome of process of managing for the whole logistics companies. As the model used for this study coupled with the findings suggested ELS competitive advantage are linked to two critical resources/capabilities, logistics managers who decide to build up competitive advantages should give attention to how they can re-engineer their supportability resources and revamp logistics management skills for ELS development. The development of logistics management skills is a key issue that logistics companies should pay more attention to. Improvements relating to inventory tracking, container scheduling, transportation cost, and data sharing with suppliers, are required for the achievement of a better ELS competitive posture by logistics firms in China. The sustenance of adequate logistics supportability resources is another key issue to logistics firms in China. Making supportability resources available for logistics market development, meeting competitive prices, advance facility and technology from suppliers, and offering competitive credit terms to customers depends on improvements of infrastructure facility and cost advantages/disadvantages. In short, logistics firms need to coordinate supply chain activities and leverage function of learning so as to build up the logistics supportability resources to customer satisfaction and market success.

\section{Conclusions}

ELS have been examined by a large number of scholars. However, most of these studies focused on the issues related to e-logistics system as a whole and its internal characteristic. This research explores internal components of ELS and their exogenous influence factors and tests their relationship each other in Chinese Logistics Companies (CLC).Therefore, Consistent with the current situation of Chinese logistics industry, the investigation results perfectly inflect that the main problems of the most logistic enterprises in China and also provide valuable insights into the current status of ELS in CLI.

\section{Limitations and Further Research}

One of the contributions of the study is the development of the extensive set of interrelationships in each component of ELS and exogenous influence factors. Practically, the paper also provides some helpful suggestions for the development of ELS in CLC. However, there are a number of limitations to be approach adopted. For example, although the research demonstrates 
significant findings, it does not cover all factors related to ELS. Additional research needs to extend the study to other factors and business contexts to reinforce our confidence in the generalizability of the findings of this study. Second, the study provides an insight of ELS for logistic company which stays in the same level of development. Hence, for the next phase of our research, it is interesting to investigate more logistic company in different countries. ELS is widely popular topic in Korea. Therefore, it is meaningful to develop a comparative analysis on both Korean and Chinese logistics industry. This would provide the significant value for both of countries. In short, although the study provides theoretical and practical insight into ELS in CLC, future research is needed to extend the proposed model to reinforce our confidence in the findings of this study.

\section{Acknowledgement}

In this paper, the research was sponsored by the Major Project Cultivation Program of XI ZANG MIN ZU University (Project No.).

\section{Reference}

[1]Chellappa, R. and Pavlou, P., "Perceived information security, financial liability and consumer trust in electronic commerce transactions", Logistics Information Management Volume 15 Number 5, 2002 pp. 358-368

[2]Cheng Wang and Yue Chen(2006), The Utilizing e-logistics: case studies in Sweden and China, http://epubl.luth.se/1653-0187/2006/10/LTU-PB-EX-0610-SE.pdf

[3]Daly \& Cui, E-logistics in China: basic problems, manageable concerns and intractable solutions, Available online 4 September 2002

[4]Gerstle D.,(2004) Selection/Development of Reliable Power Supplies, Reliability, Maintainability, \& Supportability, April Volume8, Number 2,2004

[5]John J.Coyle, Edward J.Bardi and C.John Langley,Jr.(2003), TheManagement of Business Logistics, A Supply Chain Perspective, the 7th Edition.

[6]Miyazaki, J. and Fernandez, K., "The antecedents and consequences of trust in online-purchase decisions”, Journal of Interactive Marketing 16 (2): 47-63, 2000.

[7]Piplani, R., S. Pokharel, and A. Tan, "Perspectives on the use of information technology at third party logistics service providers in Singapore," Asia Pacific Journal of Marketing and Logistics 16, 1 (2004), pp. 27-41.

[8]Zhang Liang-jie, Yadav Pooja, Chang Henry, Akkiraju Rama, Chao Tian, Flaxer David, Jeng Jun-Jang (2001), ELPIF: An E-logistics Processes Integration Framework: Based on Web Services, IBM T.J. Watson Research Center.2001.

[9]Yung-yu TSENG, Wen Long YUE and Michael A P TAYLOR,(2005), THE ROLE OF TRANSPORTATION IN LOGISTICS CHAIN, Proceedings of the Eastern Asia Society for Transportation Studies, Vol. 5, pp. 1657 - 1672, 2005

[10]National Bureau of Statistics of the people’s Republic of China, 2006 